\title{
21
}

\section{APPROPRIATING BERLIN'S TEMPOHOMES}

\author{
Ayham Dalal, Aline Fraikin, and Antonia Noll
}

\section{The appropriation of refugee camps: a growing research agenda}

Flags, logos of humanitarian organizations, textiles, barbed wire, electricity cables, concrete blocks, swamps, zinco sheets, tents, and appropriated shelters are a few of the things that one would expect to see in a refugee camp. Since the early 2000s, not only has knowledge about the spatialities of refugee camps increased (cf. Agier 2016), but their designs and layouts have also diversified. In a previous study, we examined how the need to plan "better" camps in Jordan and Berlin has led to the creation of new camps and shelter designs that seek to foster control over refugees (Dalal et al. 2018). In this chapter, we will expand on this debate by showing how refugees find ways to subvert the initial designs and appropriate the camp for the purpose of dwelling (Heidegger 1971).

In the literature, the appropriation of physical space is linked to the ways in which social space is perceived and theorized (Bourdieu 2018; Lefebvre 1991). In studies involving refugee camps, however, the appropriation of space is never addressed explicitly. Instead, it is perceived through two concepts: urbanization and agency. For instance, it is generally suggested that appropriations would eventually lead to the urbanization of camps (Agier 2002; Misselwitz 2009; Herz 2013; Dalal 2014). This would also underline the refugees' agency (Sanyal 2010; Ramadan 2013), in contrast to their theoretical passiveness (Agamben 1998), which presents appropriation as a political action (Maqusi 2017). In our research, we extend this argument by demonstrating that the appropriation of these camps is driven by a conflict in the understanding and use of space:

1 Humanitarian technocratic planning seeks to produce manageable camps (using handbooks, manuals, and standardized regulations), so that refugees are protected and contained safely in shelters 
2 Refugees seek to create social spaces of meaning, to inhabit the space or, precisely, to dwell

This argument was portrayed earlier in the Zaatari refugee camp, where appropriations were explained as a result of the conflictual relationship between a humanitarian "far order" and a local and socio-cultural "near order" (Dalal 2014). In this chapter, we explore this relationship in the newly designed and built Tempohomes in Berlin.

To understand how spaces are being planned and subsequently appropriated in the camp, we use grounded theory and combine various methods of data collection, namely qualitative interviews and "co-mapping" (Dalal 2020), which allow both researchers and interviewees to map the changes within a certain space over time, often accompanied by sketches seeking to document socio-spatial constellations that are difficult to understand solely based on oral descriptions. Moreover, participatory observations allow the researchers to directly address particular appropriations within the space of the container, while observing how the space is being used. In addition, we conducted 18 interviews and mappings of the camp on different scales, which helped to understand the spatial arrangements of various Tempohomes in Berlin (Columbiadamm, Alte Jakobstraße, Wollenberger Straße, Quittenweg, Ostpreußendamm, and Refugium Buch) between 2018 and 2019, and Karl-Marx Straße in 2020; to explore how appropriations are linked to refugee backgrounds and family conditions (single travelers, extended families, or women-headed families); and to consequently understand the Tempohome planning and observe appropriations. It also allowed us to conduct theoretical samplings (Charmaz 2006), from which the case study was selected.

\section{Tempohome: a new type of camp}

A "Tempohome" is a specific type of camp that emerged in Berlin as a response to the comparatively large influx of refugees to the city in 2015. It was designed by a special task force at the Berlin State Office for Refugee Affairs (Landesamt für Flüchtlingsangelegenheiten, or LAF) to accommodate 200 to 500 refugees, supervised locally by an operator (a for-profit or non-profit organization). Inside the camp, refugees are housed in rows of adjacent container units. Each container unit is composed of three identical containers $(2.3 \times 5.9$ meters $)$ attached to each other. The unit is accessed from the middle: a shared space used as a small lobby, entered through a porch and cantilever, and equipped with a small kitchenette and washroom. The two adjacent rooms are equipped with standardized furniture, which can differ slightly from one Tempohome to the next, yet generally include: two beds, two mattresses, two wardrobes, one fridge, one table, and two chairs. When fully furnished, however, a container room in a Tempohome leaves its inhabitants with only $7 \mathrm{~m}^{2}$ of space to move (Darweesh 2019). This affords refugees a very limited space in which to live and to share with others. 
Moreover, a Tempohome is conditioned by strict safety regulations such as "fire protection." These regulations apply to all housing in Germany. In a Tempohome, however, they pose a major challenge for refugees due to the scarcity of space and the design of the container. For instance, gardening boxes or other refugee belongings cannot be placed in front of the windows outside the container since they would hinder refugees' exit in case of fire. Curtains, which are usually hung on the porches to increase privacy, cannot be attached to the metal structure of the container as they would block the main door. Curtains and carpets inside the container are also frowned upon as they might cause a fire if they touch the heaters for an extended period of time. Nor is inserting screws or nails into the container walls permitted. The furniture should remain inside the container and be protected, and the space inside the container should be cleaned. "It is like a hotel room," said a camp operator, to underline the fact that these containers are meant as temporary accommodations and thus not suitable for dwelling (interview in Karl-Marx Straße, July 2020). But how do refugees appropriate the container under these strict and minimal conditions?

\section{Leila's family: converting a group of containers into a dwelling}

When visited in August 2019, Leila, her husband, and their three sons had been living in a Tempohome for three years. Leila is a 48-year-old Palestinian from Syria who left the Yarmouk camp in December 2012. Between 2012 and 2016, her family lived between Syria and Lebanon, until her young sons fled to Europe. In August 2016, they settled in a Tempohome in Berlin, and, for about six months, they moved between rooms until they settled down when their parents arrived at the same Tempohome.

According to regulations, the family was eligible for one full container unit. Living inside three containers of about $40 \mathrm{~m}^{2}$, the five-member family had to appropriate the space and rearrange it anew. Unlike other camps where appropriations can be practiced extensively and are thus easy to spot, appropriating Tempohomes occurs within the clearly demarcated boundaries of the container and are therefore subtle and less visible. This does not mean that a visitor to a Tempohome would not notice new elements that have been added to the containers by refugees, but the way these appropriations are linked to each other and the rationale behind them is less obvious. As such, we aim to illustrate how these appropriations are linked to each other, and how they are intended to create a dwelling that transcends the initial design of the Tempohome as a standardized shelter.

The transition from a group of containers into a dwelling began with symbolic gestures such as cooking, re-organizing space, and adding carpets. As the eldest son explained:

When mom arrived, the first thing I noticed was that we started to use the oven in the kitchen and that she started to organize things around. 
Using the kitchen to prepare meals is an important dimension that is deeply intertwined with the socio-spatial dynamics of dwelling (Bourdieu 1970). Bringing a carpet into the rooms not only adds more warmth but also makes them multifunctional when needed. For instance, food can be placed on the floor atop a plastic sheet to keep it clean, and mattresses can be arranged on it to create seating corners when needed. In a normal context, adding a carpet to one's own house is not a surprising practice. However, in a Tempohome, it requires negotiations with the camp managers since it contradicts the rules: a carpet inside the container can be dangerous as it could ignite quickly in case of fire. Luckily, Leila and her family managed to convince the operators of the Tempohome and were allowed to add a few carpets to beautify the space and increase its adaptability.

Of course, appropriations within the container often include other practices of personalization, such as adding photos and decorations. But the significance of this case is its ability to show how the sum of the various spatial practices results in a "dwelling arrangement" in contrast to the initial "shelter design." For instance, one of the rooms was appropriated to carve out a private space used as a sleeping space for Leila and her two youngest sons. Initially, the room was furnished to temporarily accommodate two refugees using a bunk bed and two wardrobes. Instead, the family dismantled the bunk bed-a practice that Leila's sons had learned during their stay in the emergency centers - and placed the single beds next to one another. Since they are five members, the family was eligible for an additional single bed. The bed was added and placed next to the other two, creating a longer bed used by Leila and her younger sons during the night, and as a space for napping when the husband and the eldest son returned from work during the day. The rest of the room was appropriated as a storage space with a larger fridge composed of the two small fridges initially installed in each of the rooms. This practice was also observed in other containers, especially among families.

As argued elsewhere (Dalal 2020), refugees tend to dismantle the standardized elements of the humanitarian technocratic planning, reassembling the objects differently in order to create spaces for dwelling. In the same room, a small table with a TV and a gaming console was added to entertain the youngest sons during the day. A smaller table was added in the kitchen, providing Leila with additional space to prepare the meals.

While not all family members were able to sleep in one room, the other remaining room was utilized as a multi-functional space: a "living space" during the day and a "living room" during the night. Having been sheltered in limited spaces that often fail to accommodate extended family structures, this practice was observed in other camps in Jordan and Lebanon as well (see, for instance, Oueishek 2018; Dalal 2020). To make use of the space, the bunk bed was not dismantled in this room, but rather pushed towards the edge. Next to it, the wardrobes were placed facing each other, creating a transitional space to the beds, and leaving enough space for the lower bed to be used for seating during the day. The remaining part of the room is used occasionally for gathering and receiving guests, and primarily as a dining area. Initially, each room is furnished with a small table and two chairs 
for the two refugees to be sheltered within. In Leila's case, however, the physical dimensions of the shelter posed an "invisible" challenge for the family to gather at one table. As she explained:

As you can see, the room is very small. When I cook, we push the table to the center, and try to squeeze five chairs around it, otherwise, we won't all fit . . .

After having meals, the table is pushed against the wall, freeing up a bit of space for several chairs or a mattress to be put on the ground, either for receiving guests or sleeping. As the eldest son who sleeps on the upper bunk explained:

Every day, you need to go up and down [the bunk bed], and I barely can jump because the ladders are hidden behind the wardrobes. . . . Sometimes when I don't have the energy, I get the mattresses down and I sleep on the ground.

While functioning as a bedroom for the father and his son at night, the mattress is removed in the morning and placed on the bunk bed again to facilitate the use of the room as a "living space" during the day.

One of the main challenges faced by refugees while trying to dwell in a Tempohome, or in any camp shelter in general, is the lack of space for storing personal belongings. In humanitarian designs, refugees are often imagined to be escaping drastic conditions, therefore arriving to camps with few or no belongings at all. Although this holds true for some, this is not the case for all. In fact, when performing fieldwork in the Tempohomes, the lack of space for storing personal belongings was evident, with many wardrobes packed full of clothes, leaving little space for other activities. Luckily, in Leila's case, the family was able to utilize an adjacent room entirely for that purpose. As she explained:

We are five in two rooms, so we are eligible for one more. Thus, they [the management] gave the children one ... since no one lives there, we use it for storage . . . and if we want to fry something, we fry it in the kitchen there since it is empty to avoid the smell of frying oil in our own living space.

This means that the resulting dwelling arrangement was not only limited within the container unit that they initially received, but extended to practically four containers in which the functions and furniture were redistributed and rearranged (see Figure 21.1).

Finally, and to ensure that the newly formed dwelling space has become a private space for its inhabitants, curtains were added to the windows and door. Hanging curtains in Tempohomes is one of the most practiced appropriations, according to observations. In some Tempohomes, these practices even extend to the porch, where sheets are added to close it off fully, thus enclosing it as a dwelling space, or 


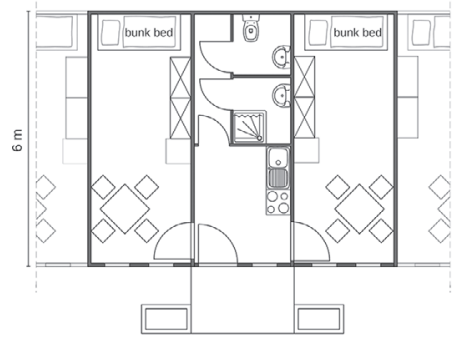

standard container units
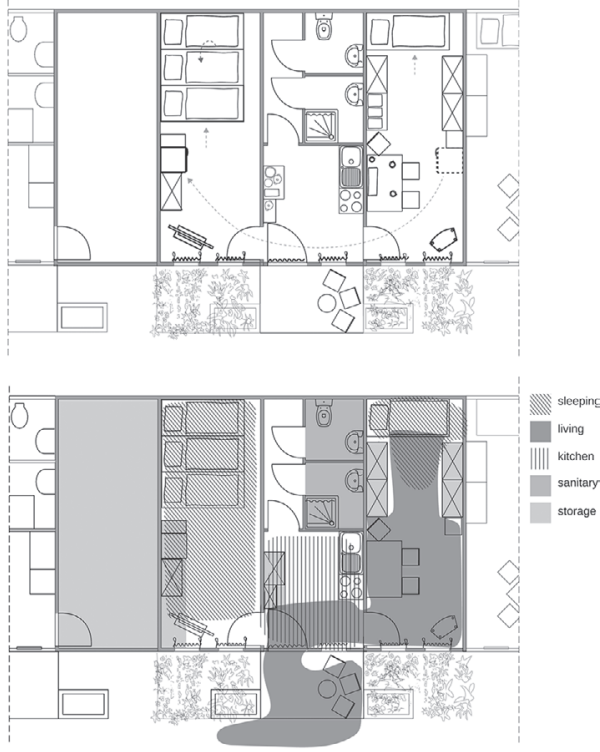

appropriated container units

FIGURE 21.1 The conversion of the standardized container into a dwelling space

Source: Authors

partly covering its sides with sheets so that it can be closed and opened as needed, thus functioning as a semi-private space. Curtains are so commonly used in dwellings that we sometimes fail to recognize their significance. Nonetheless, it is only within shelter-an abstract humanitarian space where social relations are vaguely represented - that their significance for creating privacy appears. In a camp such as Zaatari in Jordan, producing a gradient of social spaces where the private space of the dwelling is well demarcated and, above all, protected is one of the main processes that steered the transition from shelters to dwellings (Dalal 2020). Similarly, in an informal tented settlement in Lebanon, refugees built covered porches or "balconies" in order to create a transition from the very private space of the tent to the public area outside (Oueishek 2018). The reason behind this is that, in contrast to the shelter where notions of privacy are not necessarily present, a "dwelling" is first and foremost a space where a human's existential need for privacy, safety, and peace are ensured (Heidegger 1971). In order to add curtains and sheets for their spaces, refugees had to overcome further "invisible" challenges posed by the containers. Particularly, the structures of the container cannot be amended, and therefore installing screws or nails in its sheets is not allowed. In the Tempohome where Leila lived, a local technique employed to overcome this obstacle emerged: refugees used spoons or other metal elements to wedge objects such as sheets, curtains, or threads between the cracks of the containers. Because the shutters of the 


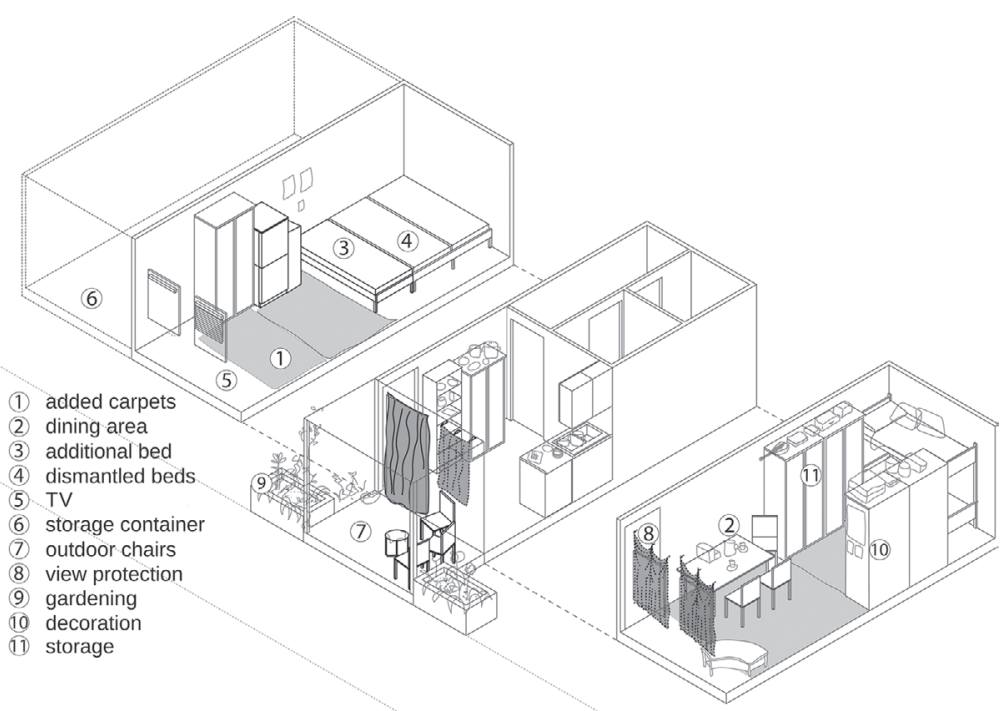

FIGURE 21.2 A perspective showing the rearrangement of elements and furniture to produce new spaces within the containers

Source: Authors

sleeping room are often closed, curtains were only added to the windows in the living space and to the kitchen where privacy and light are needed during the day. To overcome the challenging thermal conditions in the container, especially on hot summer days, the family added a curtain to the main door leading to the kitchen as well. This way, the kitchen could remain a private space, while the door could be opened to let a cool breeze into the container on hot days. Thus, a specific curtain also serves as an important element to regulate the transition between the private space of the "dwelling" and the appropriated porch (see Figure 21.2).

\section{The spatial transformation of camps}

This chapter sheds light on how refugees appropriate space in Berlin's Tempohomes. Subtle practices—-such as hanging curtains, placing carpets, dismantling beds, assembling fridges, storing luggage, and relocating mattresses, chairs, and tables-showed how the standardized layout of the container was subverted. Although the main structure of the container and its furniture remained, refugees managed to produce an alternative design that maximized the use of the space for the purpose of dwelling. By doing so, we have contributed to the debate on appropriating camps in particular and to spatial transformation in general. 
These findings have shown that changes within the physical space clearly reflect refugees' attempts to produce new social spaces. Moving beds, or squeezing them to the edge of the room, indicates an attempt to either create a "sleeping space" or a "multi-functional living room." Here, it should be noted that our observations are limited to the short periods of visits, and thus refugees' practices and uses of space extend far beyond what we have presented. Yet, our findings reveal that the factors of scale, power relations, and politics must not be disregarded when producing new social spaces within the containers. By articulating and comparing how Leila appropriated their three containers, we demonstrated that the sum of these appropriations produced a new space at a meta level: the dwelling. This means that spatial appropriations cannot be understood solely based on their immediate scale (physical space); their multi-scalar impact must be addressed as well. Changing the position of a wardrobe or adding a curtain are indeed changes to physical space that aim to create privacy and diversify the use of space. However, the sum of these practices led to the creation of a comprehensive, complex, and dynamic space, namely a dwelling, which the original container failed to offer and even hindered with its limiting regulations. This underscores the importance of scale and the connectedness between appropriations in physical space. Research needs to take into account the multiple scales on which appropriations occur, both inside and outside camps.

The second contribution of this chapter relates to the notion of spatial transformation and, in general, to the "refiguration of space" (Knoblauch and Löw 2017). The case of Tempohomes in Berlin clearly illustrates that refugees' appropriation of space is not only an interplay between physical and social spaces, but first and foremost a political act. Through a series of "tactics" (De Certeau 2013), refugees have overcome the challenges imposed on them by the limited design of the containers and their strict regulations. Hanging curtains, placing rugs, or planting flower beds are not simple acts of personalization, for they require constant negotiations with the operator, who might knock on their door and demand that these changes be removed or placed back inside the container. The container space becomes a field of spatial negotiations - a contestation of forces and power relations. Wedging a spoon between the sides of the container to hang curtains is therefore an act of resistance to disciplinary power, a demand to dwell. A better understanding of how space is transformed or "refigured," therefore, cannot be established without taking into consideration how space is disciplined and politically shaped; how it is permeated by power relations; and, most importantly, how appropriations, though sometimes "subtle" or "random," contribute to the erosion of disciplinary powers through space. In our case, this led to the emergence of a new hybrid spatial constellation: namely, a dwelling inside a shelter.

\section{Acknowledgments}

This research has been funded by the Deutsche Forschungsgemeinschaft (DFG, German Research Foundation)—project number 290045248-SFB 1265. The authors would like to thank the editors and Toby Parsloe for commenting on earlier drafts of this chapter. 


\section{References}

Agamben, Giorgio. 1998. Homo Sacer: Sovereign Power and Bare Life. Stanford: Stanford University Press.

Agier, Michel. 2002. "Between War and City: Towards an Urban Anthropology of Refugee Camps.” Ethnography 3 (3): 317-341.

Agier, Michel. 2016. "Afterword: What Contemporary Camps Tell Us about the World to Come." Humanity: An International Journal of Human Rights, Humanitarianism, and Development 7 (3): 459-468.

Bourdieu, Pierre. 1970. “The Berber House or the World Reversed.” Social Science Information 9 (2): 151-170.

Bourdieu, Pierre. 2018. "Social Space and the Genesis of Appropriated Physical Space." International Journal of Urban and Regional Research 42 (1): 106-114.

Charmaz, Kathy. 2006. Constructing Grounded Theory: A Practical Guide Through Qualitative Analysis. London: SAGE Publishers.

Dalal, Ayham. 2014. "Camp Cities between Planning and Practice: Mapping the Urbanisation of Zaatari Camp." Unpublished Master thesis. Stuttgart and Cairo: Universität Stuttgart \& Ain Shams University.

Dalal, Ayham. 2020. "From Emergency Shelters to Dwellings: On the Construction of Dwellings in Zaatari Refugee Camp, Jordan." Unpublished PhD thesis. Berlin: Technische Universität Berlin.

Dalal, Ayham, Amer Darweesh, Philipp Misselwitz, and Anna Steigemann. 2018. "Planning the Ideal Refugee Camp? A Critical Interrogation of Recent Planning Innovations in Jordan and Germany." Urban Planning 3 (4): 64-78.

Darweesh, Amer. 2019. "Planning for Asylum Accommodation in Berlin." Unpublished Master thesis. Berlin: Technische Universität Berlin.

De Certeau, Michel. 2013. The Practice of Everyday Life. Translated by Steven Rendall. 2. print. Berkeley: University of California Press.

Heidegger, Martin. 1971. "Building Dwelling Thinking." In Poetry, Language, Thought, translated by Albert Hofstadter. New York: Harper Colophon Books.

Herz, Manuel. 2013. From Camp to City: Refugee Camps of the Western Sahara. Edited by Eidgenössische Technische Hochschule Zürich. Zürich: Lars Müller Publisher.

Knoblauch, Hubert, and Martina Löw. 2017. "On the Spatial Re-Figuration of the Social World.” Sociologica 11 (2): 1-27. doi: 10.2383/88197.

Lefebvre, Henri. 1991. The Production of Space. Translated by Donald Nicholson-Smith. Oxford: Blackwell Publishing.

Maqusi, Samar. 2017. "'Space of Refuge': Negotiating Space with Refugees Inside the Palestinian Camp." Humanities 6 (3): 60.

Misselwitz, Philipp. 2009. "Rehabilitating Camp Cities: Community Driven Planning for Urbanised Refugee Camps.” Unpublished PhD thesis. Stuttgart: Universität Stuttgart.

Oueishek, Alina. 2018. "Features of the Home in the Refugee Camp: Applied Study on Al Jarahiya Camp." In Different Perspectives on the Syrian Reality, edited by Ettijahat, 17-70. Stuttgart: ibidem Verlag.

Ramadan, Adam. 2013. "Spatialising the Refugee Camp." Transactions of the Institute of British Geographers 38 (1): 65-77.

Sanyal, Romola. 2010. "Squatting in Camps: Building and Insurgency in Spaces of Refuge." Urban Studies 48 (5): 877-890. 